\title{
BASIC PROCESSES OF Black Sea Biogeochemistry
}

BY SERGEY K. KONOVALOV, JAMES W. MURRAY, AND GEORGE W. LUTHER, III

Determining the basic processes governing the biogeochemical structure of the water column is a key challenge for today's oceanographers. Knowledge of these basic processes for an aquatic system makes it possible to predict the consequences of climatic variations and anthropogenic intervention, and to numerically simulate the system's structure and evolution.

Very few marine systems are naturally hypoxic (low in oxygen), for example, areas of massive upwelling near the coasts of America and Africa, and in the Arabian Sea. Even fewer marine systems are naturally anoxic (depleted in oxygen), for example, Framvaren and some other fjords, the Cariaco basin in the Gulf of Mexico, and the Black Sea. Currently, anthropogenic eutrophication is becoming a major concern for some natural and human-made hypoxic and anoxic systems. Hypoxic and anoxic events have become a regular feature along the coastal areas of the United States (Joyce, 2000; Pew Oceans Commission, 2003) and Europe (Ærtebjerg et al., 2001). The estimated economic loss is over \$500 million per year for the Black Sea (NATO/CCMS, 2000), over $\$ 2.8$ billion per year for the Gulf of Mexico, and potentially up to $\$ 4.9$ billion per year for the region of Long Island Sound (Pew Oceans Commission, 2003).

The Black Sea (Figure 1) is an excellent natural laboratory for studying oxic and anoxic biogeochemical processes. It is also a good place to study Earth system response to climate change and variations in anthropogenic eutrophication. The Black Sea is almost closed from the world's oceans, making it possible to account for the overall budget of individual biogeochemical properties. This sea is also large enough so that synoptic, mesoscale, and seasonal processes can be averaged out. Biogeochemical properties reveal a uniform distribution of chemical constituents along equal density (isopycnal) surfaces, making it easy to trace the layers and processes of interest. Finally, the long history of oceanographic investigations of the Black Sea, which was initiated with the first publication by Andrusov (1890), has resulted in a large data set from basic observations to advanced investigations in the latest international expeditions (for more information see www.ocean.washington. edu/cruises/Knorr2003).

\section{WHAT WE CAN LEARN? Basic Features of the Black Sea} The Black Sea is a typical two-layer marine system with a strong permanent (main) pycnocline supported by an input of fresh river waters in the upper layer and saline Mediterranean waters in the lower layer. Unlike the seasonal pycnocline at the base of the surface mixed layer, the main pycnocline is never destroyed by climate-induced mixing processes. The depth and thickness of the main pycnocline vary over the sea. Winter convective mixing in the upper layer brings cold surface water deeper in the water column. This process is limited to the depth of the pycnocline, where cold waters remain preserved. The resulting cold intermediate layer (CIL) has a temperature of 8 degrees $\mathrm{C}$ at its upper and lower boundary. The CIL is the main source of oxygen for deeper waters.

The main pycnocline dramatically 


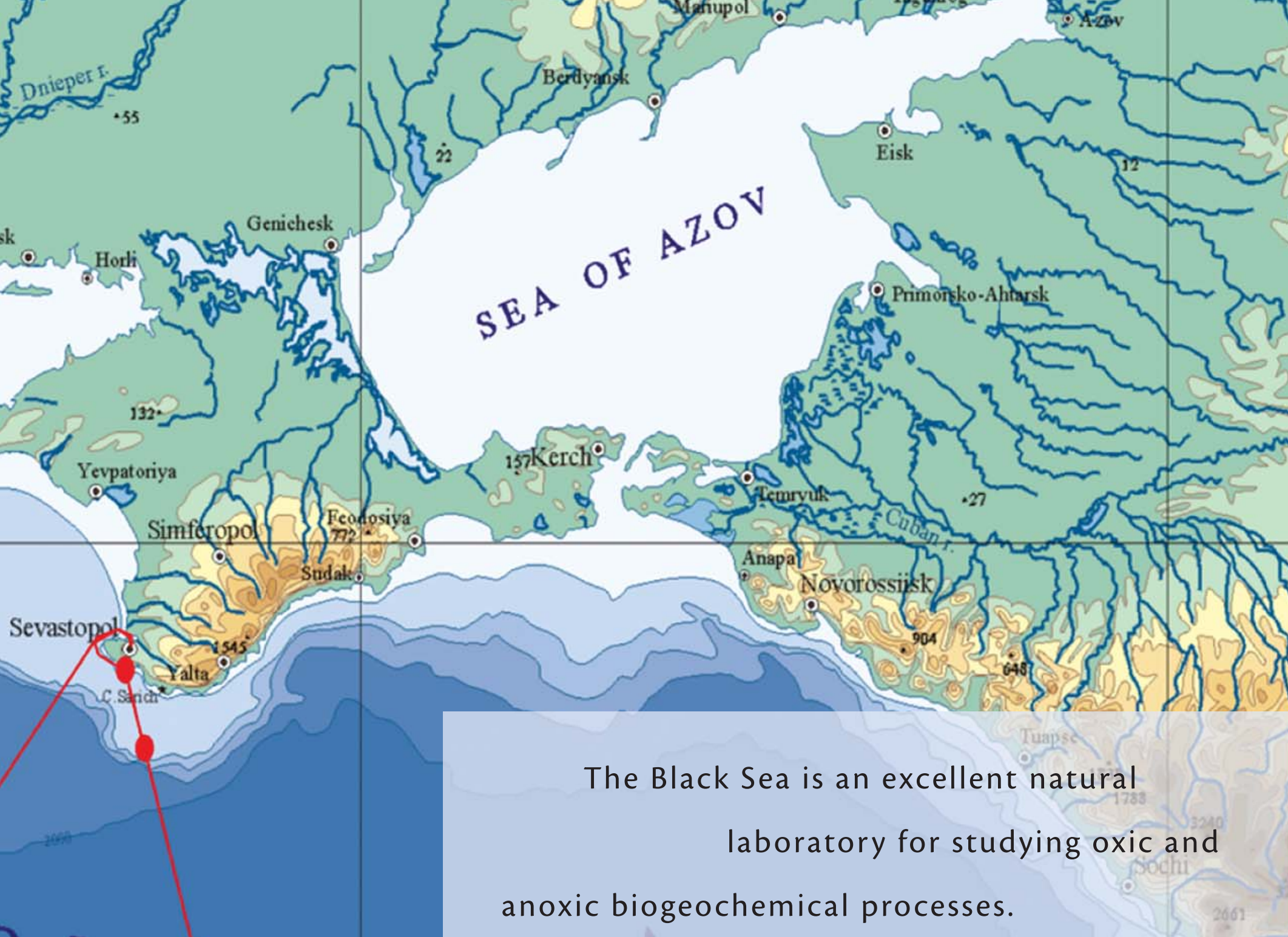




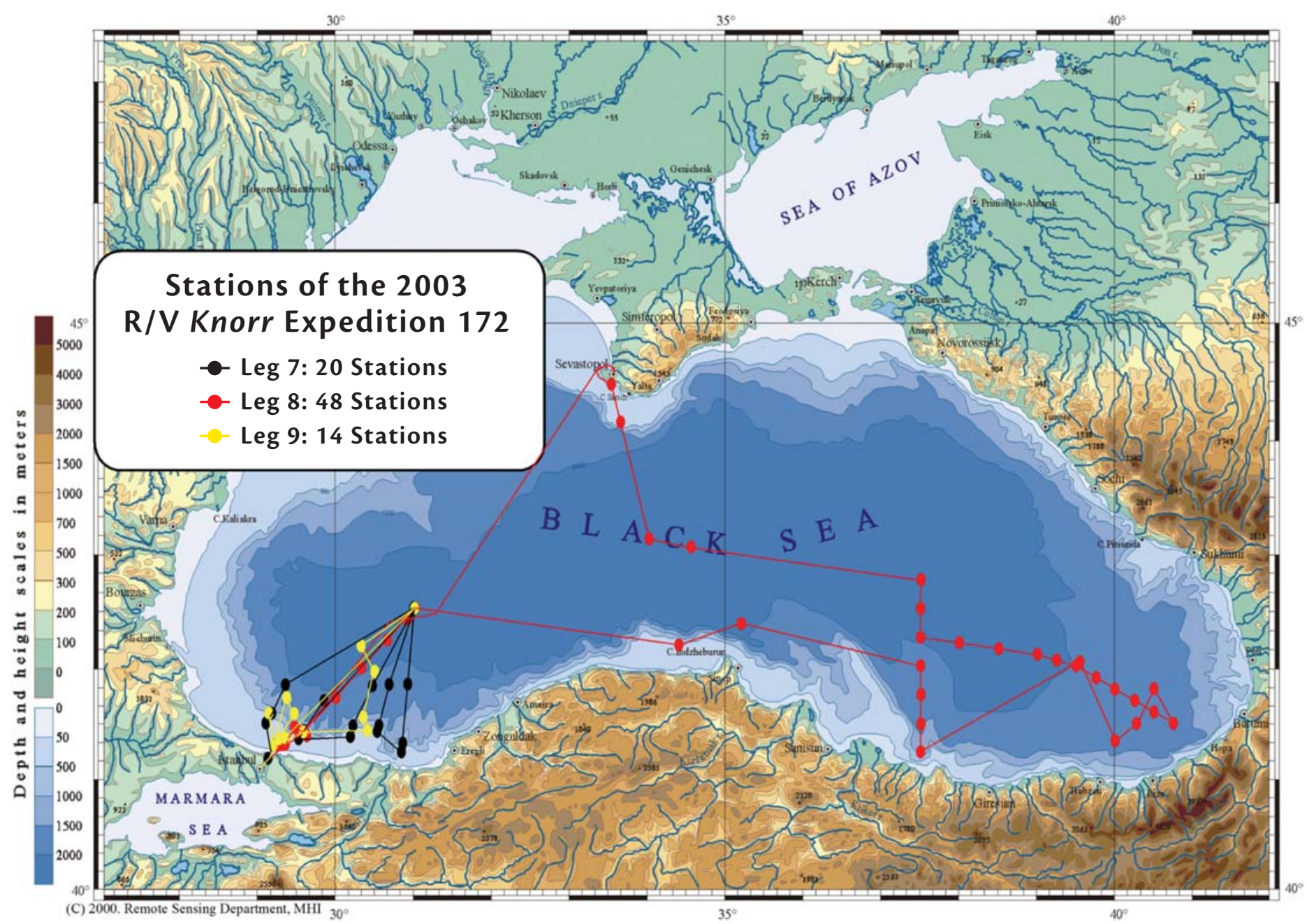

Figure 1. The Black Sea and station locations for the 2003 R/V Knorr expedition 172, Leg 7 (black), 8 (red), 9 (yellow).

restricts the downward flux of oxygen and upward flux of solutes through the water column. Similar concentrations of solutes are usually traced along isopycnal surfaces rather than at a depth

\section{Sergey K. Konovalov (sergey_konovalov} @yahoo.com) is Senior Researcher, Marine Hydrophysical Institute, Sevastopol, Ukraine. James W. Murray is Professor, School of Oceanography, University of Washington, Seattle, WA, USA. George W. Luther, III, is Maxwell P. and Mildred H. Harrington Professor of Marine Studies, College of Marine Studies, University of Delaware, Lewes, DE, USA. horizons, thus, the vertical distribution of biogeochemical properties is usually plotted versus density (or $\sigma_{\mathrm{t}}$ in $\mathrm{kg} / \mathrm{m}^{3}$ ), rather than depth (Figure 2).

The downward flux of particulate organic matter and limitations in the vertical flux of solutes in the pycnocline result in a complex biogeochemical structure (Figure 2). Under oxic conditions, organic matter is oxidized and oxygen is consumed to ultimately produce nitrate. Under suboxic and anoxic conditions nitrate and nitrite are consumed in denitrification and anammox processes (anaerobic ammonium oxidation) to produce di-nitrogen gas (Murray et al., this issue). Organic matter is bacterially respired under anoxic conditions to generate ammonium and sulfide. That part of organic matter that reaches the bottom is also respired to generate the flux of ammonium and sulfide from sediments to water. Thus, a very small part of the initial organic matter is buried in sediments and eliminated from the system.

Until recently, it was thought that the upward flux of sulfide, ammonium, and other reducers in the Black Sea was balanced by the downward flux of oxygen, nitrate, and other oxidizers to sustain equilibrium in this system over time scales of tens to hundreds of years 
(Skopintsev, 1975; Sorokin, 1982). Be-

cause reducers and oxidizers interact in a specific layer, the layer where oxygen and sulfide both exist- the "C-layer"—has been widely accepted until the suboxic zone was discovered (Murray et al., 1989, Murray et al., this issue). The existence of this suboxic zone (a layer at the interface between the oxic surface and sulfidic deep water where both concentrations and vertical gradients of $\mathrm{O}_{2}$ and $\mathrm{H}_{2} \mathrm{~S}$ are low) has revealed a paradox: the calculated vertical fluxes of reducers and oxidizers are insufficient to keep the redox balance at the upper and lower boundaries of the suboxic zone (Murray et al., 1995). The paradox is even greater when considering the undulating structure of the suboxic zone (Figure 3), which suggests independent changes in its lower and upper boundaries (Konovalov and Murray, 2001). These independent changes suggest that different processes control the oxic and anoxic layers of the Black Sea and that the oxic and anoxic subsystems respond to anthropogenic, climaterelated inputs independently.

\section{Observations}

\section{Oxic Zone}

Over the last several decades, various changes in thermohaline, biogeochemical, and biological properties of the Black Sea have been reported. Many of these changes are extraordinary in either their nature or magnitude (Ivanov and Oguz, 1998; Besiktepe et al., 1999). None of the changes traced in the 1970s to 1990s have been recognized as positive, but instead, as dramatic or catastrophic. Some changes in optical (Man’kovsky et al., 1998) and biological (Kideys, 2002) properties traced after the middle 1990s have been reported as positive. Still, the onset of an anoxic zone

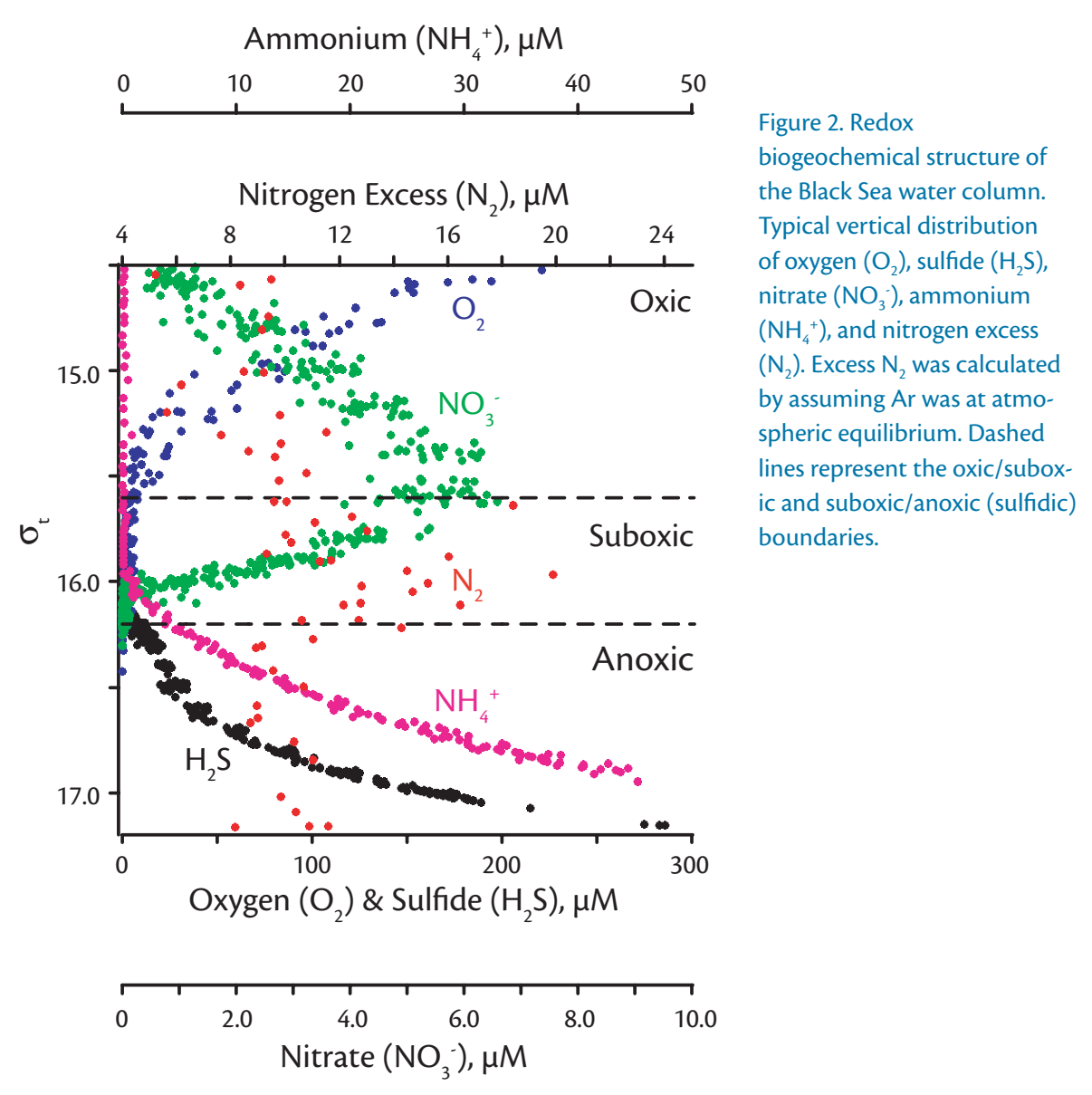

remains at about the same isopycnal surface as it was decades ago (Figure 3), raising a question about what major processes govern the Black Sea's biogeochemical structure and redox balance.

Maximum nitrate concentrations reveal variations from about $3 \mu \mathrm{M}$ in 1969 to almost $12 \mu \mathrm{M}$ in 1991, which return to about $4 \mu \mathrm{M}$ in 2003 . This variability is the result of changes in the rate of primary production and in the flux of organic matter in the water column (nitrate is produced during the oxidation of organic nitrogen under oxic conditions). Various data on the load of inorganic nitrogen to the sea (Cociasu et al., 1996) and on the rate of primary production (Sorokin, 1982; Vedernikov and Demidov, 1997) are in line with a three- to five-fold increase in nitrate during the 1970s and 1980s, then a gradual decrease in the 1990s. When maximum concentrations of nitrate are plotted versus apparent oxygen utilization, the linear fit differs from the expected oxygen consumption to nitrate production ratio by less than eight percent (Konovalov and Murray, 2001). This means that the traced dramatic variations in the distribution of oxygen and in the location of the upper boundary of the suboxic zone in the 1970s and 1980s (Figure 3) are the result of stoichiometric changes in the

Data on temporal variations in the distribution of silicates and phosphate also suggests that production and resflux of organic matter. piration of organic matter are the basic 


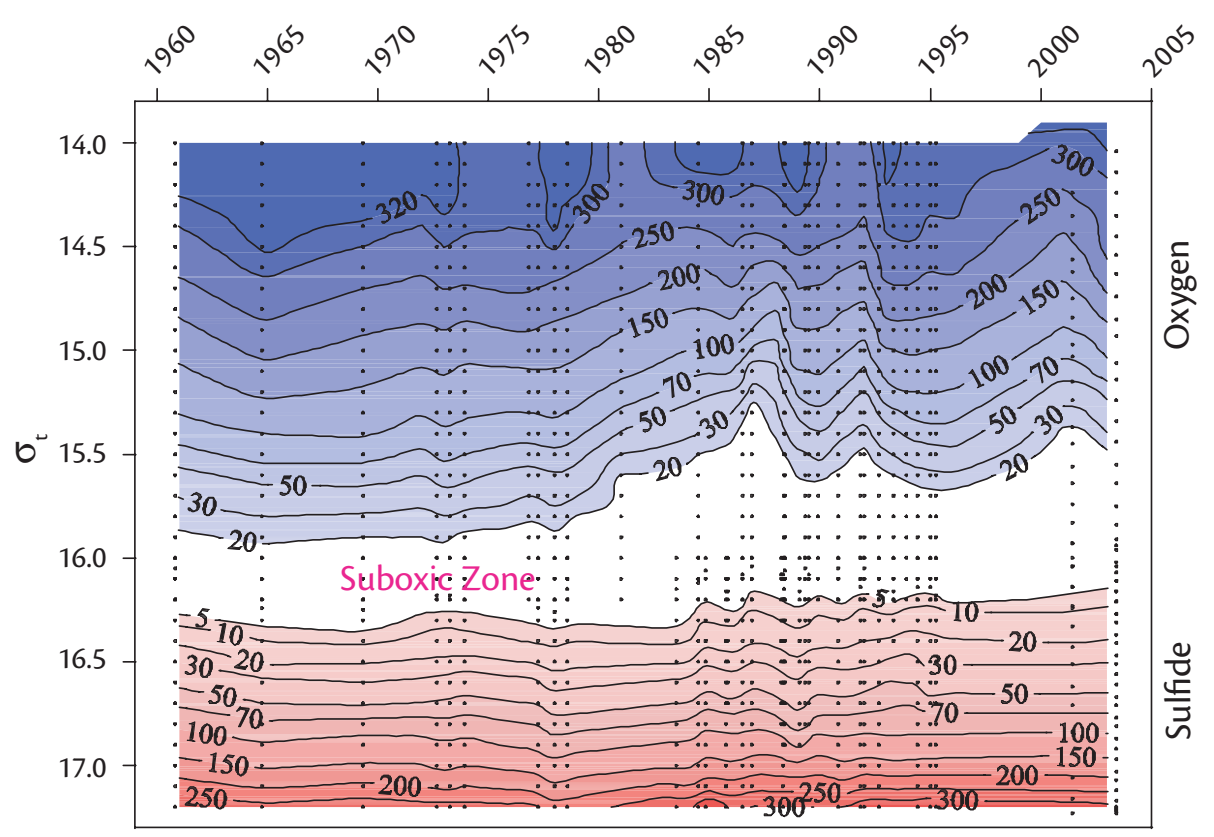

Figure 3. Temporal variations in the average distribution of oxygen (blue) and sulfide (red). Solid lines demonstrate temporal variations in the locations of specific concentrations vs. $\sigma_{\mathrm{t}} \mathrm{scale}$ (in $\mathrm{kg} / \mathrm{m}^{3}$ ). Individual dots represent the actual location of the cruise-averaged data points. The suboxic zone reveals minor variations for the period before the middle 1970s and dramatic variations for the period after 1980 .

processes governing the biogeochemical structure of the Black Sea. Inventory of silicates in the euphotic layer decreased about ten-fold (Cociasu et al., 1996) in the period of intensive eutrophication in the 1970s and 1980s when the load of inorganic nitrogen supported higher primary production and consumption of silicates in excess of the load of silicates to the sea. Inventories of inorganic nitrogen, phosphate, and silicates in the oxic layer below the euphotic zone varied in parallel, following stoichiometry (Konovalov and Murray, 2001), suggesting the very same source of these nutrientsrespiration of organic matter.

Another process that is usually considered to be important for the biogeochemical structure of aquatic systems is advection. Spatial and temporal variations in the Black Sea vortex have been traditionally considered to control the vertical distribution of all biogeochemical properties. This consideration appears to be true if plotting biogeochemical properties versus depth, but variations in the intensity of circulation result in isopycnal re-distribution of water (Figure 4a). Water-column (isopycnal) stratification and biogeochemical properties vary in parallel (Figure $4 \mathrm{~b}$ ).

Physical processes, which are very important in determining the Black Sea's biogeochemical structure, include those related to winter convective mixing and those related to the evolution of the Mediterranean waters in the Black Sea (the Bosporus plume) (Murray et al., 1991; Ozsoy et al., 1993; Ivanov and Samodurov, 2001). These processes affect cross-isopycnal fluxes of biogeochemical properties on different time scales, providing an active exchange between the surface layer and the CIL, and active transport of CIL biogeochemical properties to the suboxic and anoxic layers. The latter process includes entrainment of Black Sea waters to the Bosporus plume from the oxic layer and intrusion of the Bosporus plume waters to the suboxic and anoxic layers.

Winter mixing results in the flux of oxygen to the CIL and a flux of nitrate and other nutrients from the upper pycnocline to the euphotic zone. For example, the distribution of nitrates that was distorted in the central western gyre in spring of 1993 became isopycnal by the fall (Figure 5). Simple calculations (Eremeev et al., 1996) suggest that the process of winter convective mixing provides the flux of nitrate to the euphotic zone, which might equal the annual load of inorganic nitrogen by the Danube River. As winter mixing also provides a similar flux of phosphate and silicates, intensive "after-winter" blooms of diatoms in the central part of the Black Sea are usual after severe winters.

The flux of cold surface water to the CIL results in lower temperatures and higher oxygen concentrations in the CIL's core. Elevated concentrations of oxygen (Figure 3) have been observed during the years of the lowest temperature in the CIL's core: 1964, 1972, 1976, 1985, 1993, and 2003. The CIL's ventilation signal spreads progressively deeper in the pycnocline over the following four to six years. A linear correlation between temperature and oxygen in the pycnocline is expected if the intensity of oxygen consumption does not vary. Data in Figure 6 reveal two periods of linear correlation between temperature and oxygen in the pycnocline, suggesting that oxygen consumption varies in a narrow range within every period, and the intensity of winter ventilation drives temporal variations in 

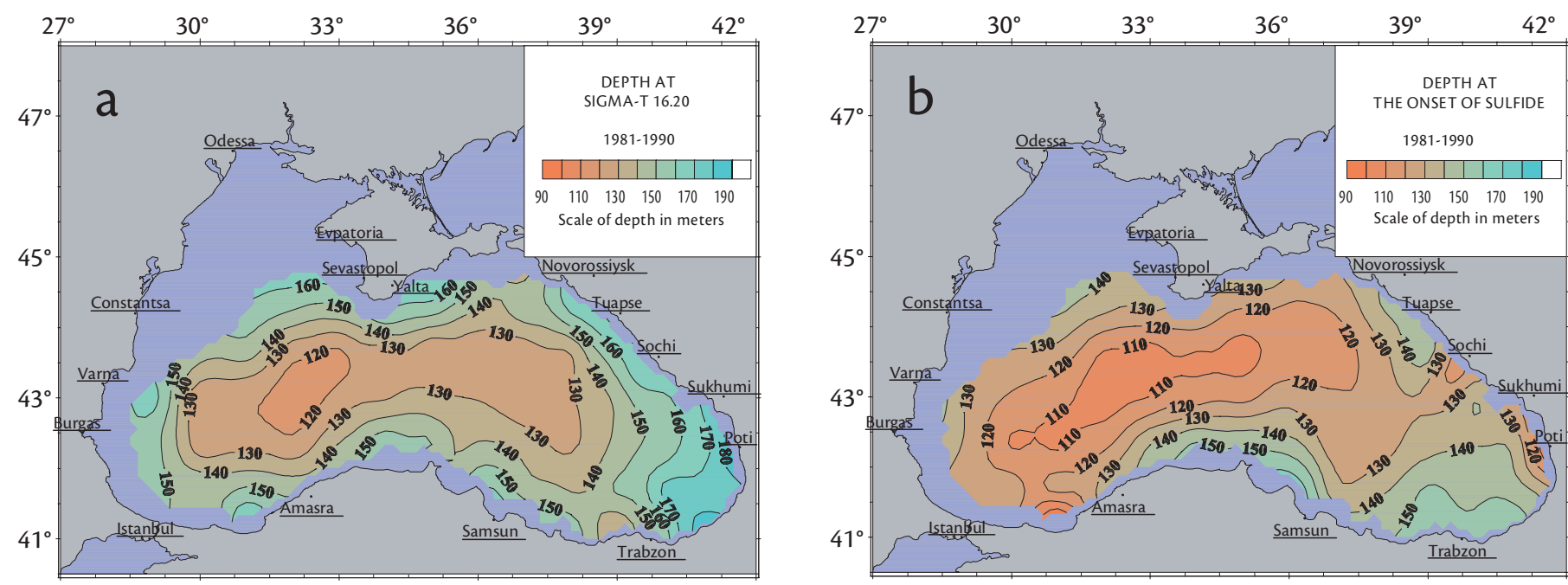

Figure 4. Decade-averaged spatial variations in (a) the depth of $\sigma_{\mathrm{t}}=16.20$ (in $\mathrm{kg} / \mathrm{m}^{3}$ ) and (b) the depth of sulfide onset. The onset of the anoxic zone (b) varies in parallel with depth of the main pycnocline (a). It shows isopycnic advective redistribution of all solutes, rather than cross-isopycnic fluxes governing the biogeochemical structure.

the Black Sea's biogeochemical structure.

In the late 1970s and 1980s, the effect of intensive eutrophication (increase in the load of nutrients to the sea and in primary production) dominated the system. Eutrophication resulted in dramatic changes in various biological, biogeochemical, and optical properties (Ivanov and Oguz, 1998; Besiktepe et al., 1999). The structure of biological communities shifted towards more intensive recycling of organic matter at the level of jellyfish (Oguz et al., 2001a), rather than at higher trophic levels. During this period, the rate of oxygen consumption in the main pycnocline and even in the CIL exceeded its physical influx (Konovalov and Murray, 2001). The upper boundary of the suboxic zone shoaled regardless of the minor changes in the level of the onset of anoxia.

A thick suboxic zone and uncorrelated variations in the upper and lower boundaries of the suboxic zone lead to the hypothesis put forth Konovalov and Murray (2001), which states that the ver- tical flux of oxygen is consumed by oxidization of organic matter and maintains the biogeochemical structure of the oxic layer, rather than controlling the onset of anoxia. Should this hypothesis be true, it makes the oxic layer of the Black Sea similar to any other oxic marine system. In particular:

- The processes of lateral advection restore and maintain an isopycnal distribution of dissolved biogeochemical species even if it is distorted by other physical or biogeochemical processes (Figure 5).

- Winter ventilation provides the flux of oxygen to the CIL (Figure 3) and the flux of nutrients from the CIL to the euphotic zone (Figure 5).

- Climate-dependent variations in the intensity of winter ventilation result in interannual oscillations in the flux and concentrations of oxygen in the main pycnocline (Figure 6) and in the position of the upper boundary of the suboxic zone (Figure 3).

- The flux of organic matter is primarily respired in the oxic layer to maintain the basic biogeochemical structure of the main pycnocline.

- Variations in the load of nutrients to the sea drive changes in primary production and the downward flux of organic matter that maintain or alter the distribution and inventory of the basic biogeochemical species (Figure 3).

\section{Anoxic Zone}

The vertical downward flux of oxygen and nitrate within the suboxic zone is too small to balance the upward flux of sulfide, ammonium, and other reduced solutes from the anoxic zone (Murray et al., 1995). This makes impossible for the suboxic zone to exist and for the onset of the anoxic zone to be stable on a time scale of decades. Several processes have been suggested that would maintain the vertical flux of electrons through the suboxic zone, couple its upper and lower boundaries, and balance the redox budget at the onset of the anoxic zone. In fact, variations in the structure of the 

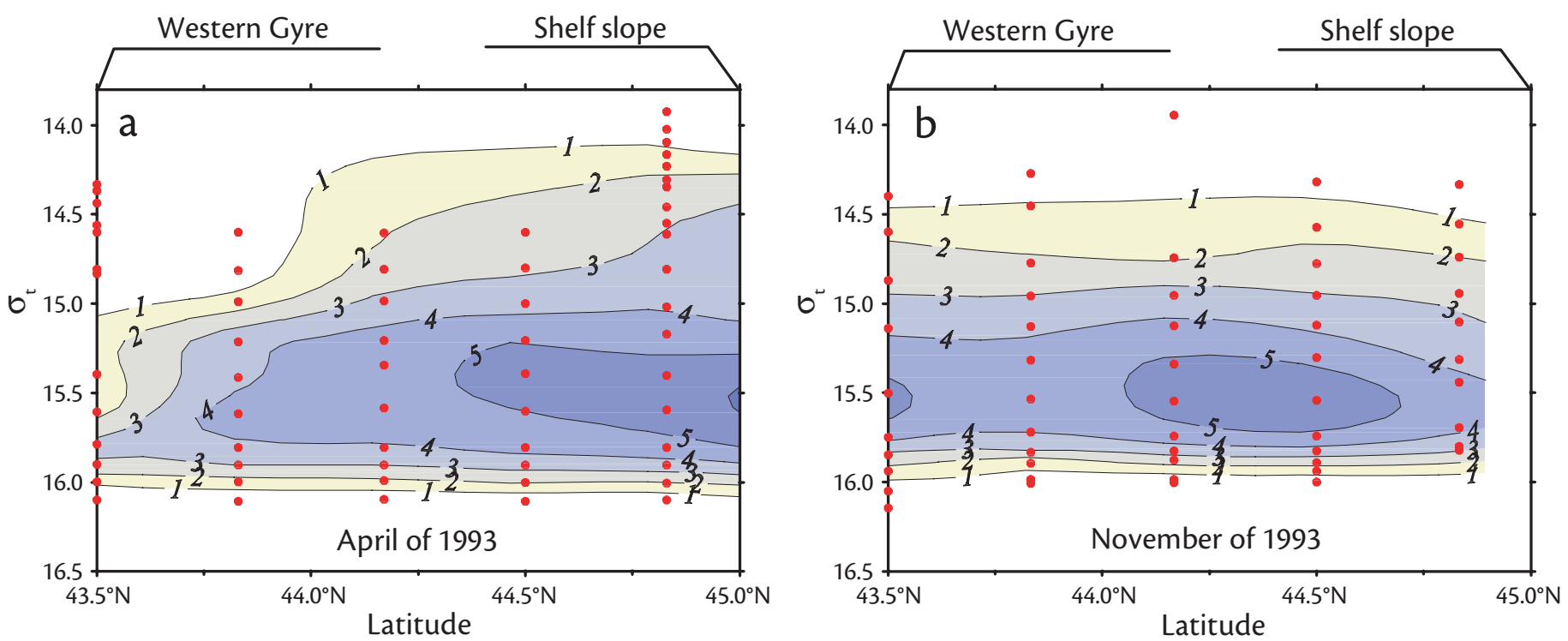

Figure 5. Variations in the vertical distribution of nitrate along the western gyre to the northwestern shelf transect in (a) April and (b) November 1993. Data for April show the result of convective mixing in the central part of the sea that intensifies cross-isopycnal exchange and brings nutrients to the upper layers. The distribution becomes isopycnal by the next fall due to lateral advection.

suboxic zone over more than four decades (Figure 3) suggest that the oxic layer of the Black Sea is vertically decoupled from the anoxic layer due to limited vertical exchange through the main pycnocline, but instead these layers are linked by lateral processes such as the evolution of the Bosporus plume (Konovalov and Murray, 2001; Konovalov et al., 2003a).

The Bosporus plume is a 1:3 to $1: 10$ mixture of oxygen-depleted waters $(\sim 50$ $\mu \mathrm{M}$ of oxygen) of the Marmara Sea and oxygen-enriched waters of the CIL ( 200 to $300 \mu \mathrm{M}$ of oxygen). The annual flux of the Marmara Sea waters into the Black Sea is, on average, $300 \mathrm{~km}^{3}$ per year. This inflow of Marmara waters results in up to $3000 \mathrm{~km}^{3}$ per year of oxygen-enriched waters of the Bosporus plume ( 150 to $250 \mu \mathrm{M}$ of oxygen) sinking and forming lateral intrusions to the suboxic and anoxic layers. The presence of lateral intrusions of water (Ozsoy et al., 1993) is revealed when vertical profiles of temperature from the western part of the sea are plotted on one graph (Figure 7a). These intrusions vary in location from station to station, but an integrated result of intrusion is pronounced for the suboxic and anoxic layers. Data from voltammetric pump profiling (which measures oxygen and sulfide with the vertical resolution of $\sim 0.5 \mathrm{~m}$ ) throughout the oxic, suboxic and anoxic layers (upper $200 \mathrm{~m}$ of the water column) of the Black Sea (Figure $7 \mathrm{~b}$ ) directly prove the presence of oxygen in the Bosporus plume intrusions (Konovalov et al., 2003b).

The effect of lateral intrusion of oxygen to the anoxic (sulfidic) zone is detected by deviations of the sulfide to ammonium ratio from the expected from Equation 1 stoichiometric value of 53/16. Sulfide, rather than ammonium, is primarily oxidized when lateral intrusions of the Bosporus plume bring oxygen to the sulfidic zone. This results in a lack of sulfide, as compared to the expected stoichiometric concentration (Konovalov and Murray, 2001).
Equation 1

$$
\begin{gathered}
\left(\mathrm{CH}_{2} \mathrm{O}\right)_{100}\left(\mathrm{NH}_{3}\right)_{16}\left(\mathrm{H}_{3} \mathrm{PO}_{4}\right)+53 \mathrm{SO}_{4}{ }^{2-}= \\
106 \mathrm{HCO}_{3}^{-}+53 \mathrm{H}_{2} \mathrm{~S}+16 \mathrm{NH}_{3}+\mathrm{H}_{3} \mathrm{PO}_{4}
\end{gathered}
$$

The magnitude of these deviations from the expected stoichiometric value increases upward towards the onset of the sulfidic zone. This is in line with the vertical variations in the volume of the Bosporus plume intrusions (Figure 7a). The vertical flux of ammonium increases upward, integrating its total production in deeper layers, then it sharply decreases in the suboxic zone due to intensive consumption of ammonium (Figure 8). In contrast to ammonium, the vertical flux of sulfide starts to decrease at the $\sim 16.9 \mathrm{~kg} / \mathrm{m}^{3}$ isopycnal (Figure 8 ), which is actually $\sim 250 \mathrm{~m}$ below the sulfide onset. Consumption of sulfide exceeds its production in the upper anoxic zone, where sulfide is produced most intensively. The vertical flux of oxidants and precipitation of iron and manganese sulfides cannot account for the detected 


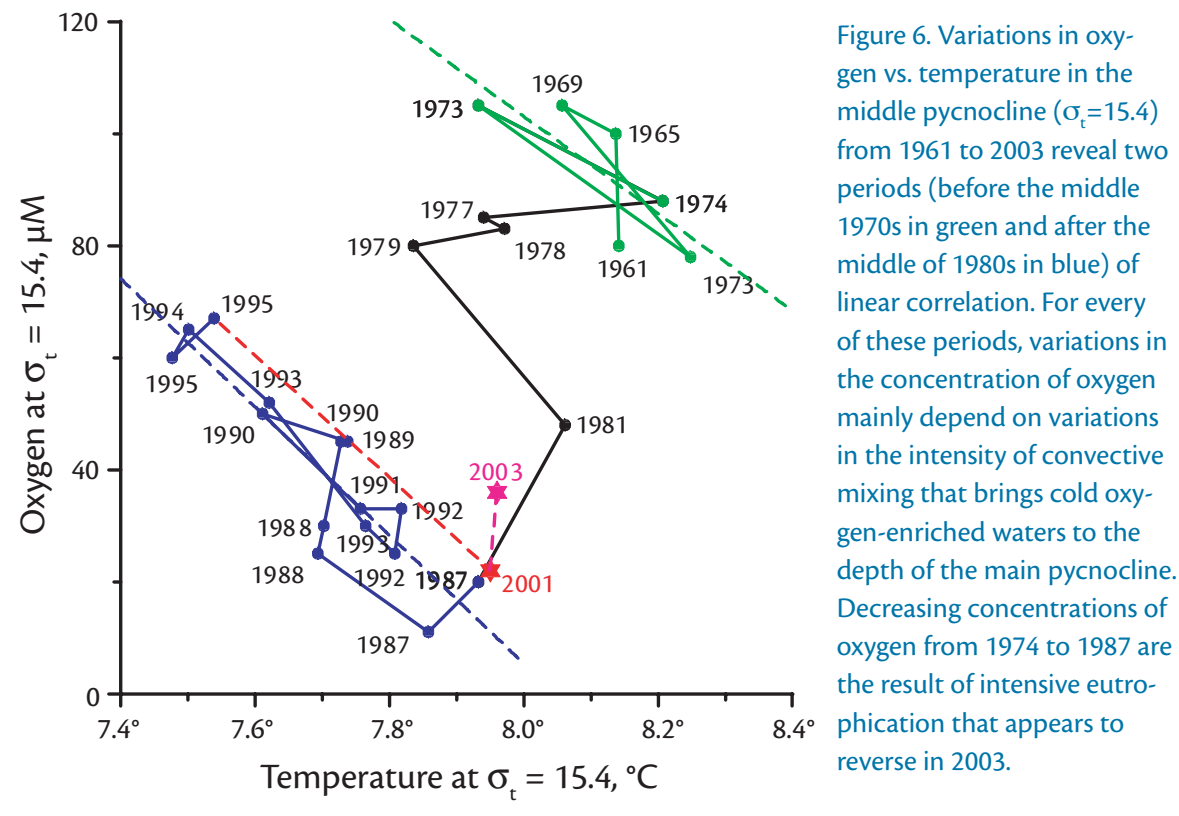

magnitude of sulfide consumption inside the anoxic zone. A three-fold decrease in the vertical flux of sulfide (Figure 8) suggests that about two-thirds of the sulfide is oxidized inside the anoxic layer due to lateral influx of the Bosporus plume waters.

Intensive consumption of sulfide inside the anoxic layer and a progressive upward increase in the lateral flux of oxygen with the Bosporus plume intrusions explains the detected relative stability in the position of the onset of sulfide over the period of several decades (Figure 3). Variations in the flux of Mediterranean waters to the Black Sea and variations in the intensity of ventilation of the main pycnocline governing the volume of the plume and the concentration of oxygen in this water are effectively smoothed for the suboxic and upper anoxic layers, as the residence time of these waters is on a time scale of decades. An upward shift of the onset of sulfide has been recently reported by Glazer et al. (submitted) to reveal the effect of a higher production of sulfide and weaker ventilation in the late 1990s.

Average concentrations of sulfide at individual isopycnals (Figure 9) highlight two periods in the recent history of the Black Sea, when (1) the flux of organic matter could not sustain consumption of sulfide and its physical flux from the anoxic zone and (2) the flux of organic matter supported production of sulfide in excess of its oxidation in the anoxic zone and its physical outflow.

In general, the basic biogeochemical structure of the anoxic zone depends on the processes of respiration of organic matter and redox processes at the onset of the sulfidic zone, but it also depends on lateral intrusion of oxygen from the Bosporus plume. The latter process decouples the upper and lower boundaries of the suboxic zone, providing consumption of a major part of sulfide inside the anoxic zone and stabilizing the onset of the sulfidic zone that cannot be balanced by vertical redox fluxes within the suboxic zone.

\section{Suboxic Zone}

The suboxic zone is defined as a layer of low concentration (less than 10 $\mu \mathrm{M})$ and low vertical gradients of oxygen above the onset of the sulfidic zone (Murray et al., 1995). The question of the nature of the suboxic zone was raised immediately after its discovery in 1988 (Murray et al., 1989). The suboxic zone was easier to discover in the late 1980s because intensive eutrophication resulted in an upward shift of the upper boundary of the suboxic zone from the $\sim 15.9$ to the $\sim 15.3$ isopycnal (Figure 3 ). Still, at that time it was difficult to explain the suboxic zone. The dominant hypothesis about how the oxic and anoxic layers interacted justified the co-presence of oxygen and sulfide (Skopintsev, 1975; Sorokin, 1982) and rejected a possibility of the suboxic zone. It has taken over ten years since the first publication describing the existence of a suboxic zone (Murray et al., 1989) to make it widely accepted and discussed for both the Black Sea (Konovalov and Murray, 2001; Murray et al., 2003a) and other oxic/anoxic marine systems such as the Cariaco basin in the Gulf of Mexico (Scranton et al., 2001).

Processes that could stabilize the suboxic zone and balance its redox budget have been discussed (Tebo, 1991; Buesseler et al., 1994; Murray et al., 1995) to finally reveal that the suboxic zone exists due to the lateral flux of oxygen with the intrusions of the Bosporus plume (Konovalov and Murray, 2001). A suboxic zone can exist when (1) the vertical flux of organic matter is big enough to consume the vertical flux of oxygen and (2) the flux of sulfide does not exceed the oxidizing potential of the Bosporus plume. Generally, a suboxic zone can exist in only those aquatic oxic/anoxic systems where processes of ventilation 

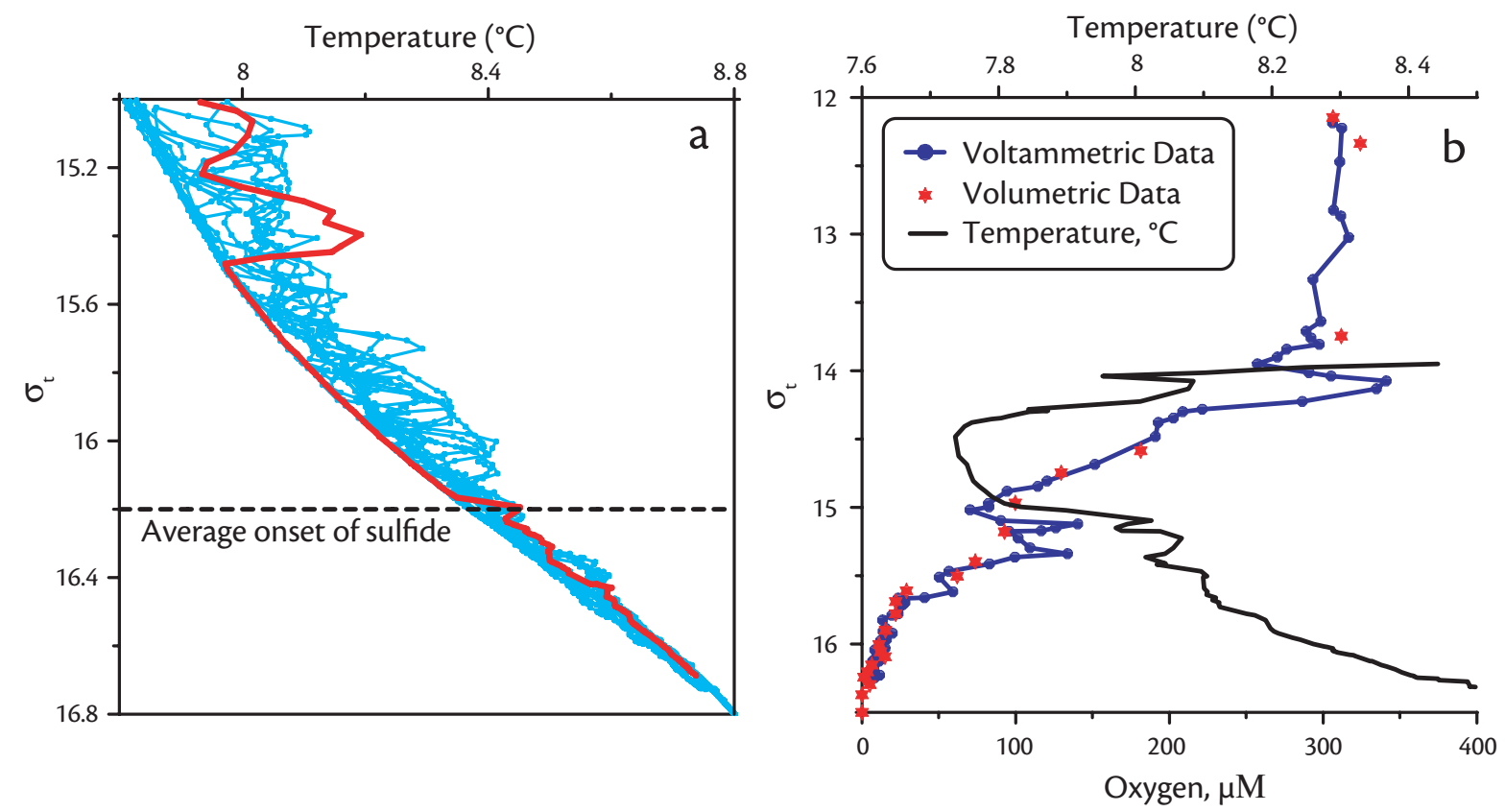

Figure 7. Anomalies in

the distribution of (a)

temperature and (b)

oxygen due to intru-

sions of the Bosporus

plume waters. Results of

voltammetric pump-pro-

filing (blue profile) are

in agreement with data

of volumetric titration

(individual red symbols),

but only voltammetric

data of a high vertical

resolution can track the

lateral intrusions of the

Bosporus plume.

provide a lateral input of oxygen to the pycnocline, which is always the boundary between oxic and anoxic layers.

The basic processes inside the suboxic zone include (1) lateral input of oxygen, (2) redox nitrogen transformations, and (3) redox cycling of manganese and iron. Respiration of organic nitrogen is also expected, as the flux of nitrate and ammonium to the suboxic zone is often below the flux of di-nitrogen from the suboxic zone (Murray et al., this issue). Still, these processes do not sustain the suboxic zone, but they mostly become possible because of the processes that control the upper and lower boundaries of the suboxic zone.

Transformation of nitrate and ammonium to di-nitrogen via de-nitrification and/or anammox is extremely important for the biogeochemical structure of both the suboxic zone and the entire Black Sea. This transformation is the only real sink of nitrogen from the system that fights eutrophication. It is also the reason that the upward flux of ammonium from the anoxic zone cannot reach the euphotic zone to fuel primary production.

Sinking particulate $\mathrm{Mn}(\mathrm{IV})$, which is the result of oxidation of dissolved $\mathrm{Mn}$ (II) in the lower part of the suboxic zone, can support oxidation of about 25 percent of the total vertical flux of sulfide, but this fraction exceeds 90 percent for the onset of sulfide (Konovalov et al., 2003a). This flux of particulate Mn(IV) is also important for redox transformations of iron, as dissolved Fe(II) is intensively oxidized by particulate Mn(IV). Additionally, adsorption and precipitation of phosphate (Shaffer, 1986) from the suboxic to anoxic zone makes it impossible for this nutrient to reach the euphotic zone and to increase primary production.

In general, the suboxic zone is not the layer where the total vertical flux of oxygen is balanced by the total upward flux of sulfide. The downward flux of oxygen is balanced by the flux of organic matter, and governs the position of the suboxic zone and temporal variations in its upper boundary. The major part of the upward flux of sulfide is balanced by the lateral flux of oxygen from intrusions of the Bosporus plume. Processes inside the suboxic zone are important, making it impossible for nitrogen, phosphate, and iron to reach the euphotic zone and to increase primary production.

\section{Numerical Simulation of the}

Biogeochemical Structure and its Evolution

Several attempts have been made to numerically resolve processes governing the biogeochemical structure of the oxic/anoxic water column of the Black Sea (Yakushev, 1998; Oguz et al., 2001b). They have been always processes-oriented and limited to an oxic/anoxic transition layer, and have never considered the total redox budget. In one of the latest attempts (Konovalov et al., 2003a; Konovalov et al., submitted), we have combined the previous achievements in modeling of physical exchange (Ivanov and Samodurov, 2001) and biogeochemical processes (Yakushev, 1998; Oguz et 
al., 2001b) and extended the layer of water from the core of the CIL (isopycnal of $14.4 \mathrm{~kg} / \mathrm{m}^{3}$ ) to the bottom. The model incorporates parameterizations of major biogeochemical processes for 16 components, including particulate and dissolved organic nitrogen, nitrate, nitrite, ammonium, di-nitrogen gas, elemental sulfur, sulfide, and dissolved and particulate forms of manganese and iron. Biogeochemical processes are stoichiometrically coupled; the rates of individual processes are limited by the concentrations of reagents; and the budgets of all individual biogeochemical components are closed. These conditions have made it possible to numerically simulate the biogeochemical structure of the Black Sea (Murray et al., this issue) and to investigate the importance of individual processes (Figure 10) on its overall structure and redox budget (Konovalov et al., submitted).

The model output confirms that the vertical flux of oxygen is primarily expended to oxidize organic matter in the oxic layer. Only 4 percent of the total vertical flux of oxygen can actually support redox processes inside the suboxic zone and only 0.1 percent can get through the suboxic zone to oxidize less than 0.5 percent of the upward flux of sulfide. In total, 88 percent of the vertical flux of oxygen is spent in redox processes in the oxic and suboxic zone, while 12 percent is entrained in the Bosporus plume. This plume component of oxygen is used to oxidize, in particular, 60 percent of the sulfide inside the anoxic zone.

The evolution of the Bosporus plume is important for oxygen and sulfide, but also for nitrate and di-nitrogen. As much as 12 percent of the total nitrate supply is entrained into the plume to generate its lateral flux, which can oxidize about 6 percent of the existing sul-
Flux of Sulfide, $\mathrm{mol} / \mathrm{yr}$

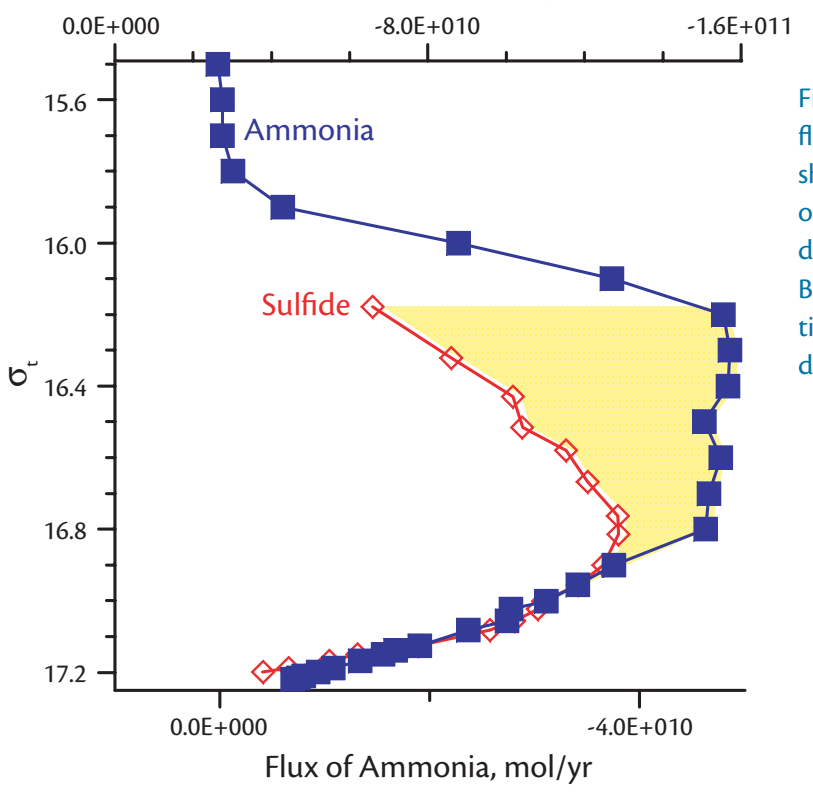

Figure 8. Profiles of the vertical flux of ammonium and sulfide show the result of consumption of sulfide inside the anoxic zone due to intrusions of oxygenated Bosporus plume waters. (Negative values mean the upward direction of the flux.)

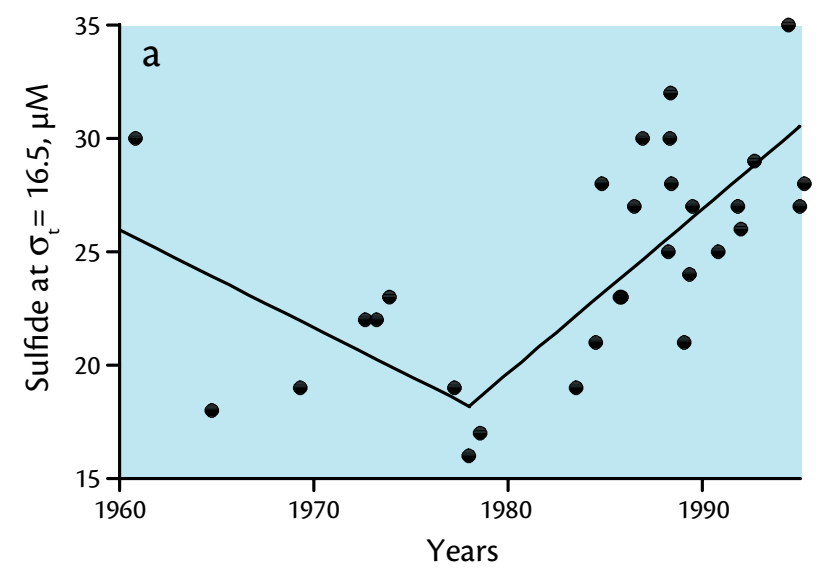

Figure 9. Temporal variations in the cruise-averaged concentrations of sulfide at isopycnal surfaces of (a) $\sigma_{t}=16.5$ and (b) $\sigma_{t}=17.0$. Data reveal two periods in the recent history of the Black Sea when production of sulfide could not compensate its consumption and flux from the anoxic zone (before 1979) and when production of sulfide increased its inventory in the anoxic zone (after 1979).

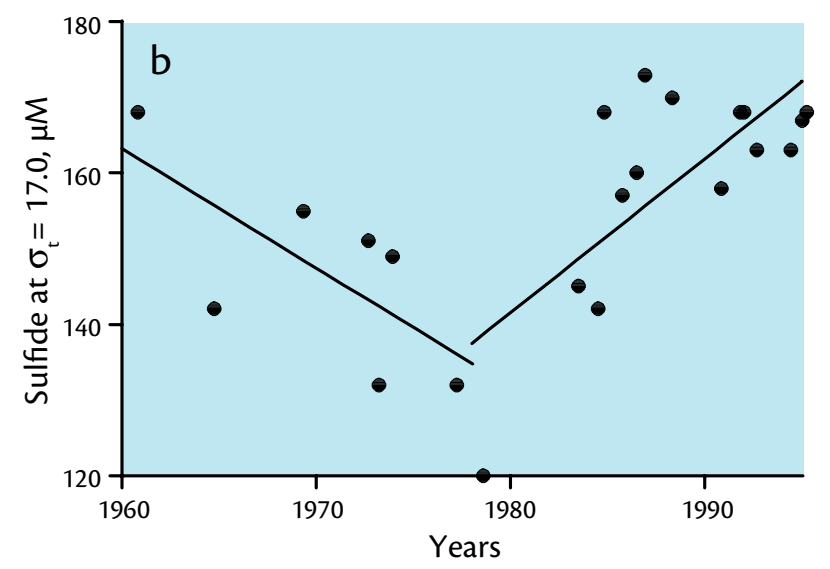



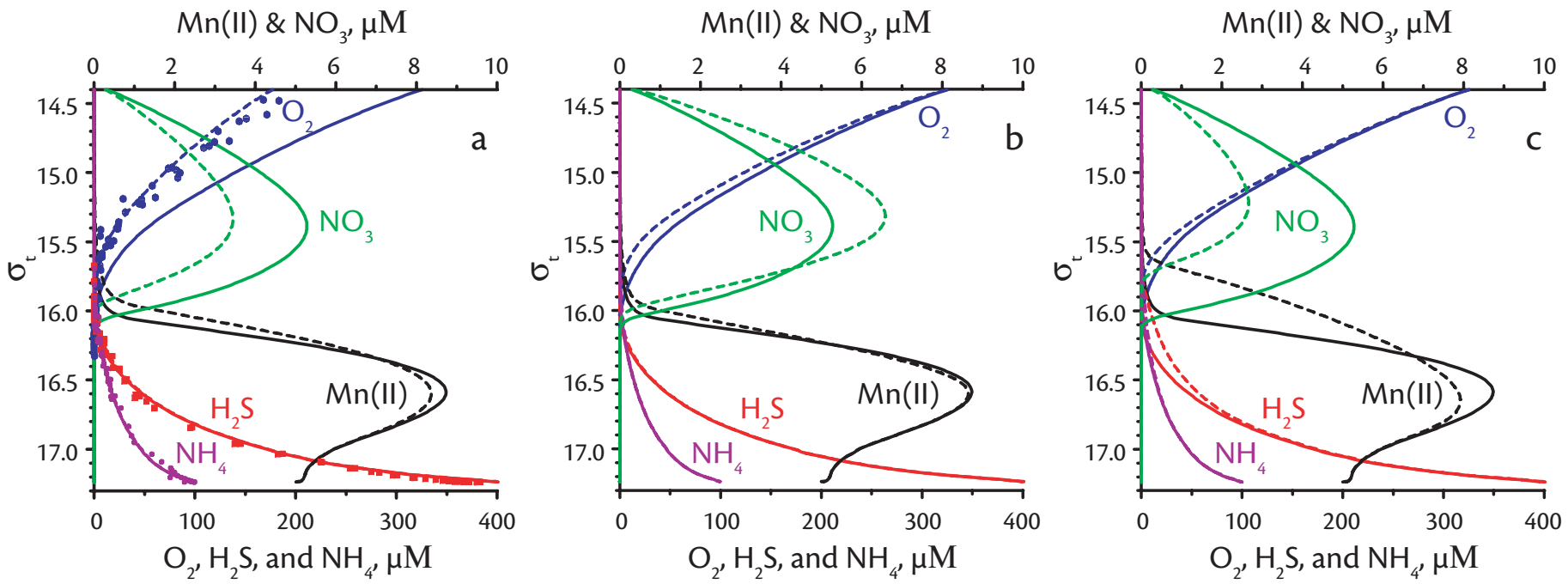

Figure 10. Numerically simulated changes in the biogeochemical structure (dashed lines) versus initial profiles (solid lines) (a) due to climate induced variations in the concentration of oxygen in $\mathrm{ClL}$, (b) due to two-fold increase in the flux of organic matter, and (c) in the absence of oxygen in the Bosporus plume, (Individual points in plot (a) are data from the 2001 R/V Knorr expedition.)

fide. Similar processes of entrainment and intrusion redistribute di-nitrogen, which is produced by denitrification and anammox reactions in the suboxic zone and support its oversaturation in the deepest anoxic layers (Murray et al., 2003b).

Oxidation of 25 percent of the total sulfide by sinking $\mathrm{Mn}$ (IV) oxides is the most important redox process for the lower boundary of the suboxic zone.

Over 80 percent of the sulfide is produced in the anoxic water column due to respiration of organic matter, while about 20 percent is produced in upperlayer sediments to sustain the observed sulfide profile. The total simulated budget of sulfide suggests excess production over consumption; however, the concentrations of sulfide in the deepest waters should almost double before the upward flux of sulfide exceeds the oxidizing potential of the Bosporus intrusions and results in a quick shallowing of the onset of sulfide.

Numerical experiments demonstrate that the observed decrease in the concentration of oxygen in the CIL from $\sim 300$ $\mu \mathrm{M}$ in 1993 to $\sim 200 \mu \mathrm{M}$ in 2001 can explain the observed changes in the structure of the oxycline and location of the upper boundary of the suboxic zone over that period (Figure 10a). In line with the results of observations in the $2001 \mathrm{R} / \mathrm{V}$ Knorr expedition (http:// ocean.washington.edu/cruises/Knorr2001), the onset of sulfide and ammonium show minor changes in their position at the scale of $\sigma_{t}$, while the upper boundary of the suboxic zone moves from the $\sim 15.8$ to $\sim 15.5$ $\mathrm{kg} / \mathrm{m}^{3}$ isopycnal.

Another numerical experiment (Figure 10b) demonstrates that a two-fold increase in the flux of organic matter at the upper boundary results in variations in the biogeochemical structure of the Black Sea, which are similar to those observed in the 1980s. The increased flux of organic matter results in an upward shift of the upper boundary of the suboxic layer (Figure 3) and an increase in the maximum concentration of nitrate. The onset of the sulfidic zone reveals minor changes, but the budget of the anoxic zone becomes unbalanced and suggests an ongoing increase in the inventory of sulfide and ammonium similar to observed data (Figure 9). Finally, if the concentration of oxygen in the Bosporus plume is set to zero, the simulated changes in the biogeochemical structure reveal disappearance of the suboxic zone (Figure 10c). The onset of the sulfidic zone moves upward to reach the oxycline, establishing a new biogeochemical structure that is similar to those oxic/ anoxic systems where the suboxic zone does not exist. This model proves that the existence of a suboxic zone in the Black Sea and in other oxic/anoxic systems is due to the presence of lateral intrusions of oxygenated waters.

\section{ACKNOWLEDGEMENTS}

This work is a part of the following projects: NSF OCE 0096365; NSF MCB 0132101; NSF OCE 0081118; NATO CLG 9791211; CRDF UG1-2432-SE-02. 四 


\section{REFERENCES}

Ærtebjerg, G., J. Carstensen, K. Dahl, J. Hansen, K. Nygaard, B. Rygg, K. Sørensen, G. Severinsen, S. Casartelli, W. Schrimpf, C. Schiller, J.N. Druon, and A. Künitzer. 2001. Eutrophication in Europe's Coastal Waters. Topic report 7/2001. European Environment Agency, Copenhagen, 86 pp.

Andrusov, N.I. 1890. Preliminary report on the Black Sea cruise. Izvestiya imperatorskogo Russkogo geographicheskogo obschestva [News of the Russian Royal geographic society] 26:398-409 [in Russian].

Besiktepe, S.T., U. Unluata, and A.S. Bologa. 1999. Environmental Degradation of the Black Sea: Challenges and Remedies. NATO Science Series, 2/56. Kluwer Academic Publishers, Dorchrecht, The Netherlands, 393 pp.

Buesseler, K.O., H.D. Livingston, L.I. Ivanov, and A.S. Romanov. 1994. Stability of the oxic-anoxic interface in the Black Sea. Deep-Sea Research I 41:283-296.

Cociasu, A., Dorogan, L., Humborg, C. and L. Popa. 1996. Long-term ecological changes in the Romanian coastal waters of the Black Sea. Marine Pollution Bulletin 32:32-38.

Eremeev, V., S.K. Konovalov, and A.S. Romanov. 1996. Spatial isopycnal analysis of variations in the vertical structure of nutrients in the Black Sea waters. Marine Hydrophysical Journal No. 6:23-38 [in Russian].

Glazer, B.T., G.W. Luther, III, S.K. Konovalov, G.E. Friederich, D.B. Nuzzio, R.E. Trouwborst, B. Tebo, B. Clement, K. Murray, A.S. Romanov. Submitted. Documenting the suboxic zone of the black sea via high-resolution real-time redox profiling. Deep-Sea Research II.

Ivanov, L. and T. Oguz. 1998. NATO TU-Black Sea project ecosystem modeling as a management tool for the black sea, symposium on scientific results. NATO ASI Series. Kluwer Academic Publishers, Dorchrecht, The Netherlands. 2/47. Volume 1, 377 pp. and Volume 2, 396 pp.

Ivanov, L.I. and A.S. Samodurov. 2001. The role of lateral fluxes in ventilation of the Black Sea. Journal of Marine Systems 32:159-174.

Joyce, S. 2000. The dead zones: Oxygen-starved coastal waters. Environmental Health Perspectives 108:A120-A125.

Kideys, A.E. 2002. Fall and rise of the Black Sea ecosystem. Science 297:1482-1484.

Konovalov, S.K. and J.W. Murray. 2001. Variations in the chemistry of the Black Sea on a time scale of decades (1960-1995). Journal of Marine Systems 31:217-243.

Konovalov, S.K., J.W. Murray, G.W. Luther, K.O. Buesseler, G. Friederich, B.M. Tebo, A.S. Samodurov, M. Gregoire, L.I. Ivanov, A.S. Romanov, B. Clement, and K. Murray. 2003a. Oxygen fluxes, redox processes and the Suboxic zone in the Black Sea. Pp. 566-577 in Oceanography of the Eastern Mediterranean and Black Sea: Similarities and Differences of Two Interconnected $\mathrm{Ba}$ sins, A. Yilmaz, ed. Proceedings on the Second International Conference on Oceanography of the Eastern Mediterranean and Black Sea held February 23-26, 1999, in Athens, Greece. TUBITAK Publishers, Ankara, Turkey.

Konovalov, S.K., G.W. Luther, III, G.E. Friederich, D.B. Nuzzio, B.M. Tebo, J.W. Murray, T. Oguz, B. Glazer, R.E. Trouwborst, B. Clement, K.J. Murray, and A.S. Romanov. 2003b. Lateral injection of Oxygen with the Bosporus plumefingers of oxidizing potential in the Black Sea. Limnology and Oceanography 48:2369-2376.

Konovalov, S.K., J.W. Murray, G.W. Luther, B.M. Tebo. Submitted. Processes controlling the redox budget for oxic/anoxic water column of the Black Sea. Deep-Sea Research II.

Man'kovsky, V.I., Vladimirov, M.V. Solov'ev, and S. Besiktepe. 1998. Optical properties of the Black Sea: Results of the CoMSBlack and TU-Black Sea programs. Pp.145-161 in NATO TU-Black Sea Project Ecosystem Modeling as a Management Tool for the Black Sea, Symposium On Scientific Results, L. Ivanov and T. Oguz, eds. NATO ASI Series 2/47(2). Kluwer Academic Publishers, Dorchrecht, The Netherlands.

Murray, J.W., H.W. Jannasch, S. Hojo, R.F. Anderson, W.S. Reeburgh, Z. Top, G.E. Friederich, L.A. Codispoti, and E. Izdar. 1989. Unexpected changes in the oxic/anoxic interface in the Black Sea. Nature 338(6214):411-413.

Murray, J.W., Z. Top, and E. Ozsoy. 1991. Hydrographic properties and ventilation of the Black Sea. Deep-Sea Research 38 (Supp. 2):S663-S689.

Murray, J.W., L.A. Codispoti, and G.E. Friederich. 1995. Oxidation-reduction environments: The suboxic zone in the Black Sea. Pp. 157-176 in Aquatic Chemistry: Interfacial and Interspecies Processes, C.P. Huang, C.R. O’Melia and J.J. Morgan, eds. ACS Advances in Chemistry Series 244. Oxford University Press, New York, NY.

Murray, J.W., S.K. Konovalov, A. Romanov, G. Luther, B. Tebo, G. Friederich, T. Oguz, S. Besiktepe, S. Tugrul, and E. Yakushev. 2003a. 2001 R/V Knorr cruise: New observations and variations in the structure of the suboxic zone. Pp. 545-557 in Oceanography of the Eastern Mediterranean and Black Sea: Similarities and Differences of Two Interconnected Basins, A. Yilmaz, ed. Proceedings on the Second International Conference on Oceanography of the Eastern Mediterranean and Black Sea held February 23-26, 1999, in Athens, Greece. TUBITAK Publishers, Ankara, Turkey.

Murray, J.W., S.K. Konovalov, and A. Callahan. 2003b. Nitrogen reactions in the suboxic zone of the Black Sea: new data and models. Pp. 591602 in Oceanography of the Eastern Mediterranean and Black Sea: Similarities and Differences of Two Interconnected Basins, A. Yilmaz, ed.
Proceedings on the Second International Conference on Oceanography of the Eastern Mediterranean and Black Sea held February 23-26, 1999, in Athens, Greece. TUBITAK Publishers, Ankara, Turkey.

NATO/CCMS. 2000. Black Sea Integrated Coastal and Shelf Zone Monitoring and Modeling (INCOM) Program Science Plan. Report No. 248. North Atlantic Treaty Organization (NATO), Committee on the Challenges of Modern Society (CCMS), Brussels, Belgium, 49 pp.

Oguz, T., H.W. Ducklow, J.E. Purcell, and P. Malanotte-Rizzoli. 2001a. Modeling the response of top-down control exerted by gelatinous carnivores on the Black Sea pelagic food web. Journal of Geophysical Research-Oceans 106(C3):45434564.

Oguz, T., J.W. Murray, and A.E. Callahan. 2001b. Modeling redox cycling across the suboxic-anoxic interface zone in the Black Sea. Deep-Sea Research I 48:761-787.

Ozsoy, E., U. Unluata, and Z. Top. 1993. The evolution of Mediterranean water in the Black Sea: interior mixing and material transport by double diffusive intrusions. Progress in Oceanography 31:275-320.

Pew Oceans Commission. 2003. America's Living Oceans: Charting a Course for Sea Change. A Report for the Nation: Recommendations for a New Ocean Policy. Pew Oceans Commission, Arlington, VA, 166 pp.

Scranton, M. I., Y. Astor, R. Bohrer, T.-Y. Ho, and F. Muller-Karger. 2001. Controls on temporal variability of the geochemistry of the deep Cariaco Basin. Deep-Sea Research I 48:1605-1625.

Shaffer, G. 1986. Phosphate pumps and shuttles in the Black Sea. Nature 321:515-517.

Skopintsev, B.A. 1975. Formirovanie sovremennogo khimicheskogo sostava vod Chernogo morya [Evolution of the Black Sea chemical structure]. Gidrometeoizdat, Leningrad. 336 pp. [in Russian].

Sorokin, Yu.I. 1982. Chernoe more: priroda i resursi [The Black Sea: the Nature and the Resources]. Moscow, Nauka, 217 pp. [in Russian].

Tebo, B.M. 1991. Manganese (II) oxidation in the suboxic zone of the Black Sea. Deep-Sea Research 38 (Supp. 2): S883-S906.

Vedernikov, V.I. and A.B. Demidov. 1997. The vertical distribution of primary production and chlorophyll in the deep part of the Black Sea for different seasons. Okeanologiya [Oceanology] 37:414-423 [in Russian].

Yakushev, E.V., 1998: Mathematical modeling of oxygen, nitrogen, sulfur and manganese cycling in the Black Sea. Pp. 373-384 in NATO TU-Black Sea Project Ecosystem Modeling as a Management Tool for the Black Sea, Symposium On Scientific Results, L. Ivanov and T. Oguz, eds. NATO ASI Series 2/47. Kluwer Academic Publishers, Dorchrecht, The Netherlands. 